\title{
Cidades Intermediárias e Ordenação Sistêmica da Paisagem: alternativas para um planejamento urbano renovado
}

Intermediate Cities and Systemic Landscape Planning: Alternatives for a Renewed Urban Planning

Ciudades Intermedias y Ordenación Sistémica del Paisaje: alternativas para un planeamiento urbano renovado

Raquel H. Tardin-Coelho*

Juliana L. Motta Maia**

Recebido: 30 de setembro de 2019

Aprovado: 10 de maio de 2020

https://doi.org/10.12804/revistas.urosario.edu.co/territorios/a.8308

Para citar este artículo:

Tardin-Coelho, R. H., \& Maia, J. L. M. (2020). Cidades Intermediárias e Ordenação Sistêmica da Paisagem: alternativas para um planejamento urbano renovado. Territorios, (43-Especial), 1-28. https://doi. org/10.12804/revistas.urosario.edu.co/territorios/a.8308

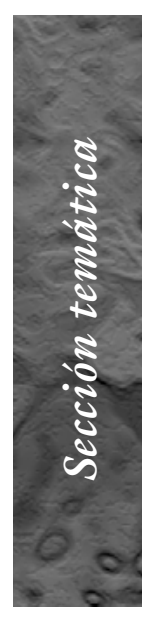

* Universidade Federal do Rio de Janeiro. Correio eletrônico: raqueltardin@ fau.ufrj.br ORCID: https:// orcid.org/0000-00024848-9939

** Universidade Federal do Rio de Janeiro. Correio eletrônico: juliana.musarq@gmail.com ORCID: https://orcid.org/00000001-9795-6276 
Palavras-chave

Cidades intermediárias;

América Latina;

Ordenação Sistêmica

da Paisagem; sistema de espaços livres; ocupação urbana; planejamento urbano.

Keywords

Intermediate cities; Latin America; Systemic

Landscape Planning; open space system; urban land occupation; urban planning.

Palabras clave

Ciudades intermedias; América Latina; Ordenación Sistémica del Paisaje; sistema de

\section{territarias 43-Especial}

RESUMO

O crescimento acelerado das cidades latino-americanas na atualidade traz consigo padrões insustentáveis de urbanização que tendem a conformar uma realidade fragmentária em relação às dinâmicas essenciais na composição da paisagem urbana -biofísicas, urbanas e socioculturais-. Isso é observado em cidades intermediárias (CIMES) latino-americanas, sobretudo com atenção a modelos de crescimento urbano extensivos e pouco controlados. Observa-se também a falta de uma visão holística sobre elas, a existência de espaços livres de ocupação urbana de grandes dimensões, esperando uma possível próxima ocupação, e a não consideração das mesmas como sistemas. Esses fatos demonstram a urgência em se pensar alternativas para o planejamento urbano dessas cidades. Diante desses desafios, o artigo busca: 1) aprofundar a abordagem de princípios, estratégias e diretrizes de atuação para a Ordenação Sistêmica da Paisagem (OSP), relativa aos sistemas biofísico, sociocultural e urbano, a partir de um sistema de espaços livres como reestruturador da futura ocupação urbana; e 2) apontar desafios e oportunidades para a aplicação prática de tais princípios, estratégias e diretrizes de atuação no planejamento de CIMES latino-americanas, como alternativas para a concepção de um planejamento urbano renovado.

\section{AbSTRACT}

The rapid growth of current Latin American cities brings unsustainable patterns of urbanization, which tend to shape a fragmentary reality in relation to essential dynamics of the urban landscape - biophysical, urban, and socio-cultural. A phenomenon is observed in Latin American intermediate cities (CIMES), especially with attention to extensive and poorly controlled urban growth models. There is also a lack of a holistic view over these cities, the existence of large open spaces, expecting to be built upon, and the non-consideration of the cities as systems. These facts demonstrate the urgency of thinking about alternatives for urban planning in these cities. Faced with these challenges, the article seeks to 1) deepen the approach of principles, strategies, and guidelines for the Systemic Landscape Planning (SysLP), related to the biophysical, sociocultural, and urban systems, based on an open space system as a restructuring element of future built-up spaces, and 2) point out challenges and opportunities for the practical application of such principles, strategies, and guidelines in Latin American CIMES planning, as alternatives for the conception of a renewed urban planning.

\section{RESUMEN}

El crecimiento acelerado de las ciudades latinoamericanas en la actualidad ha traido consigo patrones insostenibles de urbanización, que tienden a confrontar una realidad fragmentaria con relación a dinámicas esenciales en la composición del paisaje urbano - biofísicas, urbanas y socioculturales - Esto se observa en ciudades intermedias (CIMES) latinoamericanas, sobre todo con relación a modelos de crecimiento urbano extensivo y poco controlados. Se observa también la falta de una visión holística sobre ellas, la existencia de espacios libres de ocupación urbana de grandes dimensiones, esperando una posible próxima ocupación, y la no consideración de estas como sistemas. Esos hechos demuestran la urgencia de pensar alternativas para el planeamiento urbano de esas ciudades. Frente a estos desafíos, el artículo busca: 1) profundizar 
en el abordaje de principios, estrategias y directrices de acción para la Ordenación Sistémica del Paisaje (OSP), relativa a los sistemas biofísico, sociocultural y urbano, a partir de un sistema de espacios libres como reestructurador de la futura ocupación urbana, y 2) apuntar desafíos y oportunidades para la aplicación práctica de tales principios, estrategias y directrices de acción en el planeamiento de CIMES latinoamericanas, como alternativas para la concepción de un planteamiento urbano renovado.

\section{Introdução}

O crescimento acelerado das cidades latino-americanas na atualidade traz consigo padrões insustentáveis de urbanização, sejam relativos à expansão urbana dispersa ou à ocupação irregular de solo urbano e rural, com consumo descontrolado de recursos naturais, o que reforça conflitos entre preservação ambiental, urbanização, desigualdade e exclusão social crescentes (Almandoz, 2015; Ruiz-Rivera \& Lindert, 2016). Esses padrões tendem a conformar uma realidade fragmentária sob o ponto de vista de dinâmicas essenciais na composição da paisagem urbana, quais sejam: biofísicas, relacionadas aos sistemas naturais (água, vegetação, solos e topografia), urbanas, relacionadas aos sistemas urbanos (infraestruturas e assentamentos), ou socioculturais, relacionadas aos modos de vida de uma população (valores e práticas).

Essa realidade pode ser vislumbrada em cidades intermediárias (CIMES) latino-americanas, sobretudo com atenção a modelos de crescimento urbano extensivos e pouco controlados (Cifuentes-Ruiz \& Llop, 2015). Em muitos casos, essa realidade se dá devido à ausência ou defasagem de planos urbanos, ou mesmo à sobreposição de "lógicas" setoriais de ordenação urbana (Llop \& Cruz, 2017), que pouco conversam entre si e que, muitas vezes, são concebidas de modo tecnicista, genérico e abstrato, sem a consideração das especificidades da paisagem urbana em questão (Llop \& Cruz, 2017).

Soma-se a isso a falta de uma visão holística sobre as cidades (Cifuentes-Ruiz \& Llop, 2015), a existência de espaços livres de ocupação urbana de grandes dimensões que permeiam as cidades e as contornam (Bellet \& Llop, 2002) e a não consideração das mesmas como sistemas. Nos espaços livres, dinâmicas biofísicas e socioculturais ocorrem e é onde a ocupação urbana futura pode ser realizada, assim como a articulação entre as partes do contexto urbano existente e futuro (Tardin, 2013). Sobretudo, é onde a ocupação urbana pode ser pensada sob uma nova concepção, mais próxima da compreensão das dinâmicas da paisagem em sistema e rebatidas em um sistema de espaços livres reestruturador de ocupações urbanas, onde ambos, espaços livres e como um só sistema (Tardin, 2018). Esses fatos demonstram a urgência em se pensar alternativas para o planejamento urbano ocupações urbanas, estariam concebidos espacios libres; ocupación urbana; planeamiento urbano. 
${ }^{1}$ A proposta metodológica apresentada, apesar de aplicada a questões comuns a muitas CIMES latino-americanas, pode ser replicada em qualquer outro âmbito geográfico.

${ }^{2}$ Rede Internacional de Cidades intermediárias que faz parte do programa de trabalho da União Internacional dos Arquitetos (UIA) com a cidade de Lleida sobre cidades intermediárias (Programa UIA-CIMES). O programa é, atualmente, uma Cátedra da Unesco.

${ }^{3}$ Para uma classificação mais detalhada de CIMES nos paises da América Latina ver ONU-Habitat (2012).

\section{territorias 43-Especial}

de CIMEs latino-americanas sob a ótica de um pensamento integrado, que coloque em relação as distintas dinâmicas da paisagem de modo sistêmico e com atenção aos espaços livres, pensados em sistema e como reestruturadores da ocupação urbana, sobretudo em âmbito municipal.

Nesse sentido, o artigo pretende: 1) aprofundar a abordagem de princípios, estratégias -funcionais e espaciais-, assim como de diretrizes de atuação para a Ordenação Sistêmica da Paisagem (OSP) (Tardin, 2018), considerando as inter-relações entre os sistemas biofísico, sociocultural e urbano, e a partir de um sistema de espaços livres como reestruturador da futura ocupação urbana $;^{1} \mathrm{e}$ 2) apontar desafios e oportunidades para a aplicação prática de tais princípios, estratégias e diretrizes no planejamento de CIMES latino-americanas, como alternativas para a concepção de um planejamento urbano renovado. Para tanto, observamos como as CIMES têm se caracterizado na América Latina e quais desafios comuns têm sido apontados pela literatura.

\section{Cidades intermediárias (CIMES) latino-americanas: desafios para o planejamento urbano}

As CIMES são definidas por seu tamanho e função no território. São cidades com tamanho populacional e territorial médio em relação ao contexto em que se localizam, ou seja, não há um número absoluto para a definição desse critério. A rede
UIA-CIMES $^{2}$ apresenta um intervalo entre 20 mil e 2 milhões de habitantes (Llop \& Bellet, 1999). Na América Latina, as CIMES costumam ter entre $50 \mathrm{mil} \mathrm{e}$ 1 milhão de habitantes, variando de país para país ${ }^{3}$ (ONU-Habitat, 2012; UN-CEPAL \& Governo Italiano, 1998).

No que se refere à sua função, as CIMES se caracterizam por intermediar fluxos (de bens, informação, inovação, administração e outros) entre grandes áreas urbanas e pequenos assentamentos humanos, que podem ser rurais ou urbanos. São cidades ligadas a redes de infraestrutura que $\mathrm{co}^{-}$ nectam redes locais, regionais, nacionais e, por vezes, globais, o que faz delas importantes pontos nodais do sistema territorial urbano do qual fazem parte (Bellet \& Llop, 2004; Llop \& Bellet, 1999). Sendo assim, costumam ser centros de interação social, econômica e cultural e pontos de referência para um entorno mais ou menos imediato para o qual fornecem bens e serviços mais ou menos especializados (Bellet \& Llop, 2002; 2004).

Considerando essa definição, constatamos que as CIMES latino-americanas se configuram como um grupo de cidades de grande heterogeneidade, tanto em termos demográficos, como socioculturais, econômicos, territoriais, urbanos, de planejamento, entre outros. A rede UIA-CIMES (Bellet \& Llop, 2002), no entanto, nos fornece um perfil geral delas, como cidades com grande quantidade de espaços livres de ocupação urbana, extensas, pouco compactas e não muito densas 
(65,2 hab/ha na área urbana), com uma grande superfície rural e a maior parte de sua população ocupando uma pequena porção do território. Em média, 70\% de sua população ocupa um raio de $4,3 \mathrm{~km}$ e os pontos mais extremos da mancha urbana ficam, em média a $12,8 \mathrm{~km}$ de distância (Bellet \& Llop, 2002).

Em relação aos modelos de planejamento urbano adotados nas CIMES latino-americanas, a literatura indica que, em geral, se baseiam em planos de desenvolvimento e ordenação territorial (PDOT) e alguns exemplos de planejamento estratégico (Llop \& Cruz, 2017; ONU-Habitat, 2012; Steinberg, 2002). Não obstante, esses planos não têm sido efetivos, apresentando falta de corpo normativo, de concretude em relação às dinâmicas que ocorrem no território em questão, de detalhes que considerem as especificidades das mesmas, e de participação social (Llop \& Cruz, 2017). Apesar de haver alguns exemplos de participação social (UN-CEPAL \& Governo Italiano, 1998), o processo de planejamento, de modo geral, ainda carece de uma participação efetiva, que contribua para a coerência e a implementação dos planos (Cifuentes-Ruiz \& Llop, 2015)

Um dos maiores desafios das cidades latino-americanas diz respeito ao seu crescimento. Desde a década de 1980, é possível perceber que elas vêm atraindo população e atividades econômicas (ONU-Habitat, 2012), tendo hoje uma importante contribuição econômica na região e se destacando no panorama populacional como as que mais crescem (UN-CEPAL, 2017). A maioria dos países nessa região têm incentivado o fortalecimento das CIMES através de iniciativas que estimulam o desenvolvimento socioeconômico e migração para essas cidades, mas parece que a atração promovida pela qualidade de vida, pelas vantagens locacionais comparativas, $\mathrm{e}$ opções produtivas dessas cidades, têm sido mais determinantes nesses processos do que as iniciativas governamentais (Stadel, 2000; UN-CEPAL \& Governo Italiano, 1998).

O crescimento das CIMES na América Latina têm gerado pressão sobre os espaços livres de ocupação urbana, provocando uma expansão descontrolada das áreas urbanas (Bolay \& Rabinovich, 2004; Murcia \& Scornik, 2016). Dado à falta de planejamento e políticas de solo urbano, essa expansão tem sido conduzida, principalmente, pelo mercado imobiliário e assentamentos informais, que tendem a padrões dispersos e de baixa densidade (ONU-Habitat, 2012). Esse processo ainda tem sido acentuado pelo baixo poder de negociação dos municípios com o governo e stakeholders (Coy, 2003) e pela pouca capacidade técnica existente para propor um desenvolvimento urbano em grande escala (ONU-Habitat, 2012).

Esse crescimento não tem sido acompanhado de um planejamento urbano ou políticas de controle urbanísticos adequados, fazendo com que as CIMES latino-americanas, muitas vezes, se expandam “aos saltos”, sem a construção territarios 43-Especial 


\section{territorias} 43-Especial de um tecido urbano interconectado e carecendo de infraestrutura adequada. Esse padrão de urbanização tem trazido consequências desastrosas para as cidades, que apresentam déficit habitacional e de serviços básicos (ex. saneamento básico e coleta de lixo), seguidos de segregação socioespacial, do aumento no número de assentamentos informais, e de impactos ambientais, causados pelas atividades econômicas somadas ao crescimento desordenado (Bolay \& Rabinovich, 2004; Cifuentes-Ruiz \& Llop, 2015), o que evidencia uma maior vulnerabilidade às mudanças climáticas.

A carência de planejamento do crescimento urbano das cidades latino-americanas tem contribuído para a fragmentação do seu tecido urbano. Observa-se, por exemplo, grupos de edificações que se fecham para a cidade, como condomínios residenciais, shoppings, complexos empresariais e assentamentos informais (Borsdorf \& Hidalgo, 2010). A falta de regulação do mercado do solo ainda tem dificultado a existência de espaços livres públicos, que raramente contam com condições adequadas de proporção, qualidade ou localização, e se apresentam de modo fragmentado, tanto em relação à sua oferta, como relativo a seu desenho (ONU-Habitat, 2012).

Observa-se que elementos e processos biofísicos, urbanos e socioculturais, os quais possuem lógicas funcionais e espaciais intrínsecas, tendem a não ser contemplados de modo inter-relacionado na concepção de intervenções urbanas nas CIMEs latino-americanas, cujas "lógicas" de ocupação urbana se mostram pouco sensíveis às dinâmicas envolvidas em tais processos e suas interfaces. Por outro lado, a existência de espaços livres nas CIMES, tanto em seu entorno rural, como no seu tecido urbano disperso e pouco denso, representa um grande potencial para a reestruturação dessas cidades a partir da consideração do sistema de espaços livres como elemento reestruturador da atual ocupação urbana e estruturador da futura ocupação (extensão ou adensamento), assim como articulador do contexto urbano (existente e futuro). Nesse sentido, a Ordenação Sistêmica da Paisagem (OSP) se apresenta como abordagem de grande potencial para um planejamento que vise lidar com essas questões.

\section{Ordenação Sistêmica da Paisagem (OSP)}

A OSP (Tardin, 2018) parte do entendimento de que a paisagem corresponde à interação contínua do homem com a natureza, a partir de valores humanos coletivos que embasam ações e seus respectivos rebatimentos, sejam tangíveis e intangíveis, ao longo do tempo (Berque, 1984). De acordo com Berque (1984), as manifestações tangíveis e intangíveis compõem a paisagem e encontram-se inter-relacionadas, sendo matriz para a interpretação humana, a partir de seus valores próprios, e para as ações humanas, 
apresentando um processo contínuo e aberto de interação paisagem-humano-paisagem.

A abordagem sistêmica proposta considera elementos, processos e suas relações em distintas escalas, organizados entre si de modo que a parte e o todo sofrem influências mútuas e proporcionais aos desdobramentos dos fenômenos existentes e sua hierarquia na composição do conjunto, derivada de sua abrangência funcional e espacial (Capra, 1996).

A OSP considera sistemas essenciais para a garantia da vida urbana e suas dinâmicas, quais sejam: biofísico, urbano e sociocultural, inter-relacionados entre si. Tais sistemas são abordados a partir de si mesmos, ou seja, a partir dos elementos e processos necessários para que funcionem em sistema, o que condiciona a manutenção das condições atuais das dinâmicas ou sua possível transformação, assim como a abordagem de suas interfaces mútuas, como situações que devem ser concebidas de modo a potencializar o funcionamento dos sistemas. Por outro lado, aposta na concepção de um sistema de espaços livres como estruturador da futura ocupação urbana e elemento de articulação do contexto urbano existente e futuro, onde ambos, espaços livres e ocupados, e suas respectivas dinâmicas, são concebidos como um só sistema, tanto em termos funcionais como espaciais.

O sistema de espaços livres é entendido com um sistema espacial composto por peças inter-relacionadas que possibilitam a realização de dinâmicas de distintas naturezas, são interdependentes e apresentam autonomia e, através de suas dinâmicas, se relacionam com seu subsolo, seu espaço aéreo e seus entornos, ao longo do tempo (Santos, 2002).

Na OSP, as dinâmicas dos sistemas da paisagem são abordadas de acordo com (Tardin, 2018):

1. Dinâmicas biofísicas - relativas a:

a. Água - dinâmicas hidrológicas associadas aos corpos hídricos superficiais e subterrâneos, e suas interfaces com os demais elementos e dinâmicas biofísicos, socioculturais e relativos à ocupação urbana;

b. Vegetação - dinâmicas vegetais associadas às comunidades vegetais e de fauna, as interações entre elas e suas interfaces com os demais elementos e dinâmicas biofísicos, socioculturais e relativos à ocupação urbana;

c. Relevo e solos - dinâmicas relacionadas à topografia e aos solos e suas interfaces com os demais elementos e dinâmicas biofísicos, socioculturais e relativos à ocupação urbana;

2. Dinâmicas socioculturais - relativas aos modos de vida local (valores e práticas coletivos) e suas interfaces com as dinâmicas biofísicas e urbanas;

3. Dinâmicas urbanas - relativas à:

a. Infraestrutura - vias de grande porte, de alcance territorial, e territorios 43-Especial 


\section{territorias} 43-Especial 8 serviços urbanos, pensados como sistemas, e suas interfaces com as dinâmicas biofísicas e socioculturais;

b. Assentamentos - formais ou informais - rede de ruas, edificações e espaços livres urbanos (públicos e privados) -, pensados como sistemas, e suas interfaces com as dinâmicas biofísicas e socioculturais. Ressalta-se que os assentamentos informais, por sua natureza espontânea, exigem estudos que, dentro da proposta aqui colocada, ainda não foram realizados;

c. Legislação existente - normas ambientais, patrimoniais e urbanas, pensadas como sistemas, e suas interfaces com as dinâmicas biofísicas, socioculturais e urbanas.

Com base nessas dinâmicas, abordam-se princípios, estratégias - funcionais e espaciais -, e diretrizes de atuação que possam guiar o planejamento urbano de modo sustentável. Nessa proposta, as dinâmicas da paisagem se auto afetam e são geradoras de intervenções urbanas alinhadas com essas, com repercussões positivas para os sistemas planejados $\left(\mathrm{Du}^{-}\right.$ -Plessis \& Brandon, 2015; Mang \& Reed, 2012; Robinson \& Cole, 2015).

Por outro lado, a participação social é considerada parte fundamental do processo de OsP. Através da participação, busca-se o reconhecimento dos sistemas da paisagem de acordo com a população local, tanto para a valoração dos mesmos, quanto para a identificação das intenções da população para a transformação da paisagem e a construção conjunta das propostas de ordenação (Berque, 1984; Landscape Observatory of Catalonia, 2016; Steiner, 2007; Tudor, 2014).

Nesse sentido a OsP prevê (Tardin, 2018):

1. A preservação das dinâmicas biofísicas e sua assimilação, tanto funcional como espacial, pela ocupação urbana, estruturando-a;

2. A preservação das dinâmicas socioculturais e a consideração dessas na ordenação da ocupação urbana e do sistema biofísico;

3. A estruturação da ocupação urbana, considerando que o contexto urbano funcione em sistema, articulado e inter-relacionado às dinâmicas biofísicas e socioculturais.

Para tanto, a proposta teórica e prática de princípios, estratégias e diretrizes de atuação formam a base para a aplicação da OSP a fim de se alcançar os objetivos desejados.

\section{Princípios, estratégias e diretrizes de atuação para a OSP}

Os princípios e as estratégias de atuação para a OSP (Tardin, 2018) buscam alcançar condições para a realização das dinâmicas 
relativas a cada sistema e a partir de um sistema de espaços livres, de modo a favorecer o funcionamento sistêmico de tais dinâmicas, ao mesmo tempo que essas condicionam a ocupação urbana atuando como parte integrante dessa. A aplicação prática de tais princípios implica na definição de estratégias funcionais e espaciais de modo que possibilitem a realização e a incorporação das dinâmicas dos sistemas da paisagem, tanto na ordenação do sistema de espaços livres quanto na reestruturação da ocupação urbana.

As estratégias funcionais buscam garantir: 1) que os usos do solo dos espaços livres existentes, a serem ocupados ou não por infraestruturas e/ou assentamentos, e suas atividades -sejam de lazer ou produtivas-, estejam adequados às demandas dos sistemas da paisagem; 2) que as dinâmicas biofísicas e socioculturais sejam assimiladas na estruturação da futura ocupação urbana e na articulação do contexto urbano existente e futuro.

As estratégias espaciais permitem assegurar os espaços livres necessários para a realização das dinâmicas da paisagem em sistema, sejam biofísicas, urbanas ou socioculturais. São determinantes das condições espaciais dos espaços livres a serem preservados e da possível ocupação urbana futura, de modo que ambos estejam física e espacialmente inter-relacionados e favoreçam seus objetivos funcionais. Ambas estratégias influenciam a ordenação da paisagem e visam, por um lado, resguardar as dinâmicas da paisagem, essenciais para a vida - humana, fauna e flora - e, por outro, fomentar, não apenas o respeito a essas dinâmicas, mas seu potencial estruturador, como definidoras funcionais e espaciais, tanto dos espaços a permanecerem livres como da ocupação urbana futura.

Isso significa traçar diretrizes para a OsP a partir de:

1. A definição de espaços liveres a não ocupar, sua estrutura funcional (usos) e espacial, em áreas não consolidadas - relativas às áreas produtivas (ex. agricultura, pastagens) ou não-, e em áreas consolidadas - relativas aos espaços livres urbanos, públicos e privados -;

2. A definição de espaços livres a ocupar em áreas de expansão urbana, de modo sistêmico, com a definição de sua estrutura funcional (usos) e espacial;

3. A definição de áreas a adensar na ocupação urbana consolidada e sua estrutura funcional (usos) e espacial.

Nesse sentido, considera-se os os sistemas da paisagem (biofísico, sociocultural e urbano) e suas interfaces para a proposta de princípios, estratégias e diretrizes de atuação para a Ordenação Sistêmica da Paisagem.

\section{Sistema biofísico}

Busca-se o reconhecimento físico-espacial e funcional dos sistemas naturais, considerando-os como elementos e processos ativos na determinação do sistema de territarias 43-Especial 
espaços livres, na estruturação da ocupação urbana e na articulação do contexto urbano (Tardin, 2013). A partir dessa abordagem, e de acordo com a literatura sobre o tema, se identificam os seguintes princípios e estratégias de atuação:

a. Diversidade-implica em reconhecer os diversos elementos e processos naturais existentes relativos à (Benedict \& McMahon, 2006; Forman, 1995; McHarg, 1969): vegetação - mapear os ecossistemas existentes e suas formas de organização entre si; água - identificar os corpos hídricos e suas dinâmicas; topografia - identificar as particularidades do relevo e do solo local; interfaces-identificar as principais interfaces entre a vegetação, a água e a topografia e os solos, que resultem em ecossistemas com atributos funcionais e espaciais específicos;

b. Integridade-implica em considerar o pleno funcionamento dos elementos e processos naturais existentes relativos à: vegetação-verificar a possibilidade de manutenção ou restauração dos ecossistemas de forma que atenda a seu modo de funcionamento e estabeleça os espaços possíveis para o desempenho da vida da fauna e flora local (McHarg, 1969; Forman, 1995; Benedict \& McMahon, 2006; Ignatieva et al., 2011; Scarano, 2017; Vallecillo, 2018); água-identificar os espaços existentes necessários para que as dinâmicas hidrológicas funcionem integralmente, com a previsão de espaços de cheias, inundações e alagamentos (Liao, 2012; Carmon \& Shamir, 2009; Barbedo et al., 2014); topografia - manter as particularidades do relevo e do solo local, reservando os espaços com riscos de deslizamento ou desmoronamento (McHarg, 1969); interfaces - identificar as principais interfaces entre a vegetação, a água e a topografia e os solos, que resultem fundamentais para o pleno funcionamento dos elementos e processos naturais existentes entre si (Benedict \& McMahon, 2006; Forman, 1995; Ignatieva et al., 2011; McHarg, 1969; Scarano, 2017; Vallecillo et al., 2018);

c. Conectividade - contempla definir espaços essenciais para que os elementos e processos biofísicos ocorram integralmente, seja de modo contínuo ou não (Benedict \& McMahon, 2006; Forman, 1995; Ignatieva et al., 2011; McHarg, 1969; Vallecillo et al., 2018), relativo à: vegetação - identificar as conexões físicas necessárias para a manutenção ou restauração dos ecossistemas de acordo com seu pleno funcionamento, assim como espaços não contíguos que possam colaborar com as dinâmicas biofísicas por via aérea (Benedict \& McMahon, 2006; Forman, 1995; Hough, 1998; Ignatieva et al., 2011; McHarg, 1969; Vallecillo et al., 2018); água - identificar as conexões físicas necessárias para que as dinâmicas hidrológicas 
funcionem integralmente (Barbedo et al., 2014; Carmon \& Shamir, 2010; Liao, 2012).

Os princípios e as estratégias de atuação relativas ao sistema biofísico indicam diretrizes para a OSP relativas à:

1. Espaços livres a não serem ocupados: a. Áreas consolidadas - espaços livres públicos (praças, largos etc.) e privados (ex.: terrenos baldios, quintais etc.), assim como margens de corpos hídricos e outros espaços livres (contíguos ou não) que sejam fundamentais para a realização das dinâmicas biofísicas identificadas e suas interfaces (Carmon \& Shamir, 2010; Hough, 1998; Ignatieva et al., 2011; Liao, 2012; Miguez et al., 2019), as quais ocorrem no contexto urbano consolidado. Merece atenção a proposta de corredores vegetais e hídricos, que estejam pensados de modo a atender à real demanda das dinâmicas biofísicas e não baseados em dimensões ditadas por normas urbanísticas ou ambientais abstratas (Forman, 1995). Cabe ressaltar a importância dos espaços livres públicos e privados e seu desenho na realização das dinâmicas vegetais e hidrológicas, sobretudo relativas à microdrenagem (Carmon \& Shamir, 2010; Hough, 1998; Ignatieva et al.,
2011; Liao, 2012; Miguez et al., 2019). Assim como, as atividades realizadas nos espaços livres devem ser adequadas ao funcionamento sistêmico das dinâmicas biofísicas (Carmon \& Shamir, 2010; Hough, 1998; McHarg, 1969);

b. Áreas não consolidadas - espaços livres de dimensões territoriais, vegetados ou não, contíguos ou não, identificados como parte estruturante dos sistemas vegetal, hídrico e relativo à topografia e aos solos, e suas interfaces (Barbedo et al., 2014; Tardin, 2013; Benedict \& McMahon, 2006; Carmon \& Shamir, 2010; Forman, 1995; McHarg, 1969). A reserva de corredores vegetais e hídricos (Benedict \& McMahon, 2006; Carmon \& Shamir, 2010; Forman, 1995; Ignatieva et al., 2011; McHarg, 1969; Vallecillo et al., 2018) são fundamentais para a realização das dinâmicas biofísicas, assim como os demais espaços para a realização da macrodrenagem (Barbedo et al., 2014; Carmon \& Shamir, 2010). Os espaços produtivos, sobretudo relativos à agricultura e pastagens merecem atenção, para que estejam conforme as demandas das dinâmicas biofísicas (Dramstad et al., 1996).

2. Espaços livres a serem ocupados:

a. Áreas consolidadas - espaços livres privados e públicos que não territarias 43-Especial 
territorias 43-Especial apresentam interferência para a realização das dinâmicas biofísicas e suas interfaces no contexto urbano consolidado (Carmon \& Shamir, 2010; Hough, 1998; Ignatieva et al., 2011; Liao, 2012; Miguez et al., 2019);

b. Áreas não consolidadas - espaços livres territoriais que não apresentam interferência para a realização das dinâmicas biofísicas e suas interfaces na escala mais ampla do território (Barbedo et al., 2014; Benedict \& McMahon, 2006; Carmon \& Shamir, 2010; Forman, 1995; McHarg, 1969; Tardin, 2013; Vallecillo et al., 2018).

Essas diretrizes são chave para a definição dos espaços que comporão o sistema de espaços livres. Assim como, orientam o entendimento das dinâmicas biofísicas e seus desdobramentos, seja como condicionantes da concepção da ocupação urbana, funcional ou espacialmente, seja como indutores de sua articulação.

\section{Sistema sociocultural}

Busca-se o reconhecimento dos modos de vida local (valores e práticas coletivos), associando-os aos elementos e processos biofísicos e urbanos, tanto em sua dimensão físico-espacial quanto funcional, como ativos na determinação do sistema de espaços livres, na estruturação da ocupação urbana e na articulação do contexto urbano (Tardin, 2018). Ressalta-se a importância da participação social no reconhecimento dos modos de vida local e seus rebatimentos na paisagem material, seja biofísica ou urbana (Berque, 1984; Landscape Observatory of Catalonia, 2016; Steiner, 2007; Tudor, 2014). A partir dessa abordagem, e de acordo com a literatura sobre o tema, se identificam os seguintes princípios e estratégias de atuação:

a. Identidade - implica em reconhecer as manifestações da(s) identidade(s) local(is) através de valores e práticas coletivos existentes, os quais vêm associados a elementos e processos físico-espaciais e funcionais da paisagem (Besse, 2006; Relph, 1976). Assim como, implica em fomentar a manutenção de tais valores e práticas e dos elementos e processos da paisagem a eles associados de modo a permitir a permanência dos modos de vida local (Landscape Observatory of Catalonia, 2016). Isso significa reconhecer: valores-identificar como a paisagem local é vivida e percebida, sobretudo pelos moradores, assim como por frequentadores e por instituições, e quais são os valores envolvidos, como, por exemplo (Landscape Observatory of Catalonia, 2016): valores naturais e geomorfológicos, estéticos, históricos, simbólicos, produtivos, afetivos etc.; práticas - identificar as práticas coletivas - presentes e passadas - relativas 
ao cotidiano local, as quais podem ser de distintas naturezas - econômicas, sociais, sobre o funcionamento urbano etc. - e derivam dos valores existentes, sendo motivadas por esses (Berque, 1984; Besse, 2006; Lowenthal, 1975; Relph, 1976; Schama, 1995); elementos e processos físico-espaciais e funcionaisimplica em reconhecer e circunscrever os rebatimentos físico-espaciais e funcionais dos valores e práticas coletivas existentes nos elementos e processos da paisagem, sejam biofísicos ou urbanos, por exemplo, necessários para a preservação desses valores e práticas (Besse, 2006; Landscape Observatory of Catalonia, 2016). Tais elementos e processos da paisagem devem ser mantidos ou regenerados de acordo com demandas para a preservação dos valores e práticas identitárias. Ressalta-se a importância de se preservar elementos e vistas cênicas (Bolós, 1992; González Bernardez, 1981; Laurie, 1975), que permitem a coesão visual da paisagem, incluindo uma relação mais próxima entre cidade e campo, assim como percursos e marcos históricos (Bolós, 1992; Lynch, 1975), além dos demais elementos e processos citados;

b. Territorialidade - implica em reconhecer os elementos e processos socioculturais locais e seus rebatimentos físico-espaciais e funcionais relacionados às manifestações $\mathrm{da}(\mathrm{s})$ identidade(s) local(is) (Dematteis \& Governa, 2005). Objetiva-se a preservação dos territórios necessários às manifestações $\mathrm{da}(\mathrm{s})$ identidade $(\mathrm{s})$ local(is) junto aos elementos e processos envolvidos, com especial atenção às manifestações das populações tradicionais e dos demais moradores locais. Cabe identificar: agentes sociais - os agentes sociais existentes, sua organização e as relações que se estabelecem entre eles e entre eles e o território físico em questão (Dematteis \& Governa, 2005); dominios - implica em demarcar os domínios físico-espaciais e funcionais existentes e os modos de apropriação do espaço realizados pelos agentes sociais e suas dinâmicas, como por exemplo: delimitação de fronteiras, redes funcionais, divisão e ocupação da terra etc. (Besse, 2006); interfaces - identificar os elementos e processos biofísicos e urbanos que coincidem com a demarcação dos domínios físico-espaciais e funcionais existentes e os modos de apropriação do espaço realizados pelos agentes sociais e suas dinâmicas;

c. Sociabilidade-implica em reconhecer e demarcar os espaços de interação social (Dempsey et al., 2009), seus atributos físico-espaciais e funcionais, e propor a preservação desses. Esses espaços são identificados a partir do uso e apropriação coletivos existentes, considerando-se os agentes sociais envolvidos e o tempo dos usos e apropriações, seja durante as fases do ano, seja nos distintos dias e horários das tersitorias 43-Especial 


\section{territorias} 43-Especial 14 semanas; interfaces-identificar os elementos e processos biofísicos e urbanos que coincidem com a demarcação dos espaços de interação social.

Os princípios e as estratégias de atuação relativas ao sistema biofísico indicam diretrizes para a OSP relativas a:

1. Espaços livres a não serem ocupados: a. Áreas consolidadas - espaços livres públicos, como praças e ruas, e privados, como, por exemplo, quintais, que sejam fundamentais para a manutenção ou regeneração das dinâmicas socioculturais identificadas e suas interfaces, as quais ocorrem no contexto urbano consolidado;

b. Áreas não consolidadas - espaços livres de dimensões territoriais, vegetados ou não, contíguos ou não, identificados como fundamentais para a manutenção ou regeneração das dinâmicas socioculturais e suas interfaces relativas à: identidade, territorialidade ou sociabilidade. Pode haver o caso de espaços livres socio culturalmente significativos tolerarem determinado grau de ocupação, desde que as dinâmicas socioculturais não sejam abaladas em sua essência.

2. Espaços livres a serem ocupados:

a. Áreas consolidadas - espaços livres privados que não apresentam interferência para a manutenção ou regeneração das dinâmicas socioculturais e suas interfaces no contexto urbano consolidado;

b. Áreas não consolidadas - espaços livres territoriais que não apresentam interferência para a manutenção ou regeneração das dinâmicas socioculturais e suas interfaces na escala mais ampla do território.

Assim como as diretrizes derivadas dos princípios e estratégias relativas às dinâmicas biofísicas, as diretrizes acima são chave para a definição dos espaços que comporão o sistema de espaços livres, para a estruturação da ocupação urbana, seja funcional ou espacialmente, assim como para sua articulação.

\section{Sistema urbano}

Busca-se o reconhecimento físico-espacial e funcional do sistema urbano em questão, pensado em sistema, tendo em vista a estruturação da futura ocupação urbana (extensão ou adensamento), composta por infraestruturas e assentamentos, bem como a articulação do contexto urbano (existente e futuro), sendo o conjunto reestruturado a partir do sistema de espaços livres e inter-relacionado às dinâmicas biofísicas e socioculturais (Tardin, 2018). A partir dessa abordagem, e de acordo com a literatura sobre o tema, se identificam os seguintes princípios e estratégias de atuação: 
a. Pluralidade-implica em reconhecer os diversos elementos e processos urbanos existentes relativos à infraestrutura, assentamentos, suas interfaces e legislação, seguindo as seguintes estratégias de atuação: infraestrutura - vias de grande porte e serviços urbanos mapear os elementos existentes, seus tipos morfofuncionais, suas dinâmicas e as formas de organização entre si, com atenção (Mascaro, 2005; Tardin, 2013): ao alcance territorial das vias e dos serviços urbanos, e às possibilidades de mobilidade tradicional e alternativa (por água, terra e ar), e do pedestre; assentamentos - sobretudo formais, pois os informais exigiriam outros estudos - rede de ruas, edificações e espaços livres urbanos (públicos e privados) - mapear os elementos existentes, seus tipos morfofuncionais, suas dinâmicas e suas formas de organização entre si, a partir (Jenks \& Jones, 2010; Panerai, 2006): do reconhecimento da densidade construída - com atenção às taxas de ocupação, de permeabilidade, afastamentos, tamanho dos lotes e das testadas, gabarito e índice de aproveitamento do terreno -; dos espaços livres privados nos lotes; dos usos do solo - sobretudo equipamentos coletivos e centralidades de comércio e serviços -; da rede de ruas e dos espaços livres públicos e suas respectivas hierarquias e modos de mobilidade; interfaces - identificar as principais interfaces entre as infraestruturas e os assentamentos que resultem em áreas urbanas com atributos funcionais e espaciais específicos, assim como na identificação de vetores de crescimento e suas demandas; legislação - reconhecer as normas ambientais, patrimoniais e urbanas vigentes;

b. Equidade-considerar o pleno funcionamento dos elementos e processos urbanos existentes e a equidade de acesso a esses recursos de acordo com demandas coletivas (Carmona, 2009), relativos à: infraestrutura - vias de grande porte e serviços urbanos - verificar a possibilidade de manutenção ou transformação das infraestruturas e dos serviços urbanos de forma que atendam a seu modo de funcionamento, estabeleçam-se os espaços possíveis para o desempenho de suas funções, e estejam distribuídos no território a fim de atender às demandas coletivas (Cooper et al., 2009; Dempsey et al., 2009; Jenks \& Jones, 2010); assentamentos - rede de ruas, edificações e espaços livres urbanos (públicos e privados) - verificar a possibilidade de manutenção ou transformação dos assentamentos de forma que atendam a seu modo de funcionamento, estabeleçam-se os espaços possíveis para o desempenho de suas funções, e estejam concentrados no território de modo a oferecer autonomia funcional, a otimizar o uso das infraestruturas e sua distribuição, a fim de atender territarios 43-Especial 
às demandas coletivas (Cooper et al., 2009; Jenks \& Burgess, 2000; Jenks \& Jones, 2010). Especial atenção deve ser dada à distribuição de equipamentos coletivos e centralidades de comércio e serviços; à distribuição dos espaços livres públicos; e à provisão e distribuição de habitação social; interfaces - identificar as principais interfaces entre as infraestruturas e os assentamentos que evidenciem áreas estratégicas, as quais apresentam desafios para o pleno funcionamento das dinâmicas urbanas e a distribuição dos recursos infraestruturais, de modo a atender às demandas coletivas e proporcionar qualidade de vida a seus habitantes. Cabe ressaltar que equipamentos e espaços livres públicos com maior alcance de público precisarão de maior acessibilidade, e locais biofisicamente mais frágeis devem ser mais preservados do acesso facilitado, seja pelo interesse na proteção ambiental, relativo à visitação e atividades, seja para evitar uma futura ocupação urbana; legislação - verificar como as normas ambientais, patrimoniais e urbanas vigentes colaboram ou não para o pleno funcionamento das dinâmicas biofísicas, socioculturais e urbanas, entendidas em sistema (Tardin, 2018), e se as mesmas permitem ou incentivam a equidade territorial desejada;

\section{territorias} 43-Especial c. Coesão-implica em definir as partes do sistema urbano (existente e futuro) de forma a construir um todo integrado em diversas escalas, de maneira sistêmica, junto às dinâmicas biofísicas e socioculturais, e a partir do sistema de espaços livres, de modo a propor estratégias de ordenação que considerem (Tardin, 2018): 1) as peças que comporão o sistema de espaços livres urbano e territorial, as quais estão compostas por espaços que permitem a realização das dinâmicas biofísicas e socioculturais, assim como a articulação do contexto urbano - nesse caso, mesmo que não possuam atributos biofísicos e socioculturais significativos. Essas peças devem permear todo o território de maneira contínua e contígua, preferencialmente, e de modo inter-relacionado com a ocupação urbana, seja funcional ou espacialmente; 2) as interfaces entre o sistema urbano e o biofísico e o sociocultural, de modo a observar e registrar as interferências das infraestruturas e assentamentos no funcionamento das dinâmicas biofísicas e socioculturais e os desafios e as potencialidades para o pleno funcionamento das mesmas; 3 ) a assimilação das dinâmicas biofísicas e socioculturais pela ocupação urbana, tanto funcional como espacialmente, estruturando-a, de modo a ordenar seu desenho, sua implantação, seu uso etc., como parte integrante da mesma; 4) a definição de normas sobre os espaços livres a serem ocupados ou não e as 
condições de proteção ou ocupação dos mesmos a partir das legislações ambiental, patrimonial e urbana, pensadas em conjunto.

Os princípios e as estratégias de atuação relativas ao sistema urbano indicam diretrizes para a OSP relativas a:

1. Espaços livres a não serem ocupados: a. Áreas consolidadas - espaços livres públicos (praças, largos etc.) e privados (ex.: terrenos baldios, quintais etc.), assim como margens de corpos hídricos e outros espaços livres (vegetados ou não e contíguos ou não) que sejam fundamentais para a realização das dinâmicas biofísicas e socioculturais identificadas, e suas interfaces, as quais ocorrem no contexto urbano consolidado (ver, por exemplo, Ahern, 1995; Carmon \& Shamir, 2010; Cooper et al., 2009; Gobster \& Westphal, 2004; Hough, 1998; Ignatieva et al., 2011; Jenks \& Jones, 2010; Raymond et al., 2017). Assim como, aqueles espaços que, mesmo sem possuírem relevância biofísica e/ou sociocultural, apresentam potencial para articular o contexto urbano, como por exemplo, através da criação de novos espaços livres públicos (Tardin, 2013). Merece atenção a proposta de corredores vegetais e hídricos, que estejam pensados de modo a atender à real demanda das dinâmicas biofísicas e socioculturais locais e a importância dos espaços livres públicos e privados na realização dessas dinâmicas (Ahern, 1995; Carmon \& Shamir, 2010; Gobster \& Westphal, 2004; Hough, 1998; Ignatieva et al., 2011; Raymond et al., 2017). Assim como, devem ser observadas as propostas das bordas das ocupações urbanas compatíveis com as dinâmicas dos espaços de preservação biofísica (Carmon \& Shamir, 2010; Forman, 1995). Cabe ressaltar a importância de preservar espaços livres que componham corredores visuais urbanos e percursos de interesse cultural, assim como aqueles com potencial para a interação social (Bolós, 1992; González Bernardez, 1981; Jenks \& Jones, 2010; Laurie, 1975; Lynch, 1975). Ressalta-se que, quanto mais as dinâmicas biofísicas e socioculturais forem assimiladas na concepção espacial e funcional dos espaços livres, estruturando-os, mais o todo funcionará sistemicamente;

b. Áreas não consolidadas - espaços livres produtivos, em especial os que fornecem produtos para a própria cidade ou participam ativamente de sua economia, assim como margens de corpos hídricos e outros espaços livres (públicos ou privados, vegetados ou não e territarios 43-Especial 


\section{territorias} 43-Especial contíguos ou não) que atendam às condições colocadas no tópico acima: 1) que sejam fundamentais para a realização das dinâmicas biofísicas e socioculturais identificadas, e suas interfaces, as quais ocorrem no contexto urbano não consolidado, com especial atenção aos corredores vegetais e hídricos, corredores visuais e percursos de interesse cultural e social; 2) que apresentem potencial para articular o contexto urbano existente ou futuro. Atenção especial deve ser dada aos espaços necessários à macrodrenagem urbana, as áreas de risco geológico e às bordas das ocupações urbanas para que sejam compatíveis com as dinâmicas dos espaços de preservação biofísica. $\mathrm{E}$, da mesma forma que no tópico anterior, quanto mais as dinâmicas biofísicas e socioculturais forem assimiladas na concepção espacial e funcional dos espaços livres, estruturando-os, mais o todo funcionará sistemicamente.

2. Espaços livres a serem ocupados:

a. Áreas consolidadas-espaços livres (vegetados ou não e contíguos ou não) que não apresentam potencial para a realização de dinâmicas biofísicas, socioculturais, e suas interfaces, e para a articulação das partes do contexto urbano (Tardin, 2018). Pode ser considerada prioritária a ocupação de espaços livres servidos por infraestrutura de serviços e próximos a equipamentos públicos, em área formal da cidade (Jenks \& Burgess, 2000), cuja ocupação contribua para o sistema das edificações existentes, seja funcional ou espacialmente; assim como, a ocupação de espaços livres em áreas já consolidadas que necessitem de infraestrutura complementar. Cabe observar a necessidade de: 1) prover vias e serviços urbanos complementares em áreas desestruturadas; 2 ) reservar terrenos para equipamentos públicos (creches, hospitais, escolas, delegacias, bombeiros etc.) em área com boa infraestrutura urbana, mobilidade e acessibilidade. A ocupação de áreas consolidadas ainda deve julgar a necessidade de revisão das densidades admitidas e dos usos do solo, permitindo, conforme o caso, a criação de novos centros de bairro, bem como avaliar os espaços livres privados, observando o cumprimento de sua função social e biofísica (Guío Camargo, 2009) para controle da especulação do mercado imobiliário e provimento de habitação social. Por outro lado, a ocupação deve ser pensada a partir das dinâmicas dos sistemas biofísico e sociocultural, assimilando-as em 
suas propostas físico-espaciais e funcionais (Liao, 2012; Mang \& Reed, 2012; Tardin, 2018);

b. Áreas não consolidadas-espaços livres (vegetados ou não e contíguos ou não) que não apresentam potencial para a realização de dinâmicas biofísicas, socioculturais, e suas interfaces, e para a articulação das partes do contexto urbano (existente ou futuro) (Tardin, 2018), e que se sejam contíguos à mancha urbana (Panerai, 2006). Especialmente em áreas não consolidadas, a ocupação urbana deve garantir a existência e boa distribuição de (Cooper et al., 2009; Dempsey et al., 2009; Jenks \& Jones, 2010): 1) infraestruturas, 2) espaços livres públicos, 3) equipamentos urbanos, e 4) centros de bairro; com atenção à oferta de habitação social. De acordo com os argumentos anteriores, ao se propor parâmetros de uso e ocupação para essas áreas, é preciso considerar as interfaces com o sistema biofísico, de forma a respeitar sua capacidade de suporte, e com o sistema sociocultural, buscando preservar valores importantes para as comunidades. A capacidade de suporte do meio biofísico junto à consideração dos modos de vida locais, podem indicar balizadores para a definição dos limites da ocupação urbana (Cooper et al., 2009; Jenks
\& Jones, 2010). Merece atenção a identificação de espaços livres que se enquadrem nessas premissas e que não estejam cumprindo sua função social e/ou biofísica (Guío Camargo, 2009), especialmente considerando a necessidade de relocação de famílias em áreas de risco. Como no tópico anterior, a ocupação deve ser pensada a partir das dinâmicas dos sistemas biofísico e sociocultural, assimilando-as em suas propostas físico-espaciais e funcionais (Liao, 2012; Mang \& Reed, 2012; Tardin, 2018).

3. A definição de áreas a adensar na ocupação urbana consolidada e sua estrutura funcional (usos) e espacial:

De acordo com o discutido anteriormente, devem ser consideradas áreas prioritárias para o adensamento vertical e horizontal aquelas cujo adensamento seja compatível com as dinâmicas biofísicas e socioculturais presentes, e que estejam integradas ao sistema urbano existente, ou seja, com acesso às infraestruturas urbanas e ao transporte público. O processo deve levar em consideração a necessidade de prover espaços para novos usos, equipamentos urbanos, e espaços livres públicos, de modo a atender as demandas coletivas, e garantir a acessibilidade e preservação de elementos e processos biofísicos, corredores visuais -importantes para uma visão coesa do território-, assim como de percursos culturais e sociais. Ao territorias 43-Especial 


\section{territorias} 43-Especial considerar o grau de adensamento das áreas é importante observar a capacidade de suporte do sistema de infraestrutura e serviços urbanos existentes, bem como do sistema biofísico em questão. Assim como, deve-se levar em conta a preservação dos valores socioculturais que influenciam nesse quesito seja relativo à identidade, territorialidade ou sociabilidade.

Como vemos, a proposta de diretrizes para a OSP implica no reconhecimento do caráter holístico e sistêmico da paisagem, na análise de seus sistemas, e no rebatimento dessas diretrizes na legislação futura, seja no âmbito da proteção ambiental, patrimonial ou relativo ao desenvolvimento urbano.

\section{Oportunidades e desafios para o planejamento das} Cidades Intermediárias latinoamericanas a partir da Ordenação Sistêmica da Paisagem

A osp, portanto, propõe um olhar renovado em relação ao planejamento urbano ao vislumbrar a ordenação urbana a partir da compreensão dos sistemas da paisagem biofísico, sociocultural e urbano - e suas inter-relações, com foco na ordenação de um sistema de espaços livres como (re)estruturador da ocupação urbana, possibilitando a conformação do território como um todo integrado e sistêmico.

Uma importante contribuição para as CIMES latino-americanas, como apontado, está no papel protagonista dado aos espaços livres na ordenação das cidades. A reestruturação do território a partir desses espaços em sistema, não apenas propõe a ressignificação da grande quantidade de espaços livres existentes nessas cidades (Bellet \& Llop, 2002), como colabora para o reforço das relações entre a construção da cidade, os sistemas biofísicos e os modos de vida local.

Através da visão sistêmica, a abordagem traz uma perspectiva holística sobre o território, que ajuda a combater a lógica setorial identificada no planejamento urbano das CIMES na América Latina (Llop \& Cruz, 2017), possibilitando a criação de planos e políticas integradas, que respondam, ao mesmo tempo, à distintas instâncias - saneamento, transporte, habitação, segurança etc. -, e tendo por base a concretude das dinâmicas estudadas e suas interfaces, aliadas à possibilidade concreta de implementação, no território, das diretrizes propostas.

Os princípios, estratégias e diretrizes para a OSP apresentam potencial de contribuição no enfrentamento desses e de outros desafios das CIMES dessa região do globo, como, por exemplo:

Relativo ao sistema biofísico:

- Ao estruturar a ocupação urbana a partir da lógica do pleno funcionamento dos elementos e processos biofísicos existentes, a OSP traz a dimensão da natureza para dentro da cidade, colaborando para a criação de uma relação 
positiva da cidade com o meio biofísico, e garantindo a continuidade das relações humano-natureza, ao mesmo tempo que promove a sustentabilidade biofísica e urbana;

- A compreensão e incorporação das dinâmicas e elementos biofísicos no planejamento urbano das CIMEs latino-americanas podem colaborar para reduzir sua vulnerabilidade aos efeitos das mudanças climáticas, favorecer sua resiliência, e preservar a qualidade de vida, que tem sido um dos vetores de atração para essas cidades;

- O mapeamento das principais dinâmicas e elementos biofísicos a serem preservados apresenta uma possibilidade de conciliar a preservação ambiental com a urbanização, problema enfrentado não só pelas CIMES, mas por muitas outras cidades, assim como com a produção agrícola e outras atividades rurais, tão importantes nas dinâmicas das cidades intermediárias.

\section{Relativo ao sistema sociocultural:}

- No contexto de globalização e rápido crescimento urbano vivenciado pelas CIMES latino-americanas, a proteção de seu patrimônio material e imaterial colabora para preservar dinâmicas e valores locais que são importantes para sua identidade, territorialidade e sociabilidade, o que, de outra forma, poderiam se perder no processo de rápido crescimento urbano;
- A compreensão das dinâmicas socioculturais atreladas aos espaços livres possibilita identificar e preservar seus valores, atribuindo significado a esses espaços tão presentes na paisagem dessas cidades, e permitindo a continuidade da relação direta da população com o território mais amplo, característica das CIMES (Llop \& Bellet, 1999);

- A participação social, pouco presente no planejamento urbano das cidades da América Latina, traz a concretude da paisagem local para os planos, e colabora para criar plataformas de defesa e pressionar o poder legislativo para a normatização e regulamentação dos planos.

\section{Relativo ao sistema Urbano:}

- O reconhecimento das dinâmicas dos sistemas biofísico e sociocultural, integrados à concepção da ocupação urbana de maneira sistêmica, promovem a sustentabilidade urbana;

- A atenção às interfaces: 1) com o sistema biofísico - ajuda a reduzir o risco e impacto ambiental urbano e seus desdobramentos, assim como colabora para a resiliência urbana; 2) com o sistema sociocultural - ajuda a criação de planos e projetos mais consistentes, coerentes com os modos de vida local e de fácil assimilação pela população; 3 ) entre os elementos e processos do sistema urbano - auxilia territarios 43-Especial 


\section{territorias} 43-Especial na identificação das áreas críticas a serem tratadas no planejamento urbano; 4) com as legislações locais - auxilia na criação de planos e políticas públicas sistêmicas, mais coerentes e factíveis;

- A reestruturação da ocupação urbana a partir do sistema de espaços livres tende a combater os processos de fragmentação e dispersão observados nas cidades latino-americanas, ao favorecer a criação de um tecido urbano integrado, alinhado com as dinâmicas biofísicas e socioculturais, com infraestrutura, espaços livres públicos e equipamentos públicos pertinentes. Isso contribui para uma expansão e/ ou adensamento urbanos mais controlados e adequados, com menos gastos públicos e com a verificação da adequação dos vetores de crescimento identificados, colaborando para combater a desigualdade e a exclusão social. De modo geral, evita a pressão do mercado imobiliário sobre espaços livres considerados fundamentais do ponto de vista da preservação das dinâmicas da paisagem - biofísicas, socioculturais e urbanas.

Por outro lado, alguns desafios para a implantação da OSP nas CIMES latino-americanas podem ser verificados, como, por exemplo:

- A obtenção do grande número de informações necessárias para o desenvolvimento das análises e avaliações pretendidas em contextos de poucos recursos financeiros, humanos e de dados registrados;

- A necessidade de aprofundar as diretrizes sugeridas para a OSP através da proposta de parâmetros objetivos que ajudem a transformar as diretrizes urbanas em índices normativos;

- A necessidade de apoio das instituições locais para a mobilização e participação social, o que demanda tempo e recursos humanos e financeiro;

- O tempo necessário para realizar as análises, avaliações, propostas e os respectivos rebatimentos normativos, e a compatibilidade com o tempo das gestões políticas;

- A necessidade de alinhamento político das instituições locais sobre as diretrizes de OSP a serem aplicadas e a proposta de políticas públicas pertinentes e sua efetivação normativa.

\section{Conclusão}

Esse artigo buscou investigar como a Ordenação Sistêmica da Paisagem pode contribuir para um planejamento urbano renovado de CIMES latino-americanas. Para tanto, foram identificadas algumas das principais problemáticas presentes no planejamento dessas cidades na atualidade e, a partir de um aprofundamento dos princípios, estratégias e diretrizes de atuação para a OSP, foram indicados desafios e oportunidades para a aplicação 
prática de tal abordagem no planejamento das mesmas.

Ressalta-se como a proposta da OSP pode contribuir para a reversão do quadro de fragmentação espacial das CIMEs latino-americanas diante de um crescimento acelerado, seja relativo ao sistema biofísico, urbano ou sociocultural, assim como das normativas correspondentes, cuja concepção segmentada acaba por resultar em mais fragmentações. A ênfase é dada na compreensão da paisagem em sistema e na importância do sistema de espaços livres como ativo na reestruturação da ocupação urbana, onde espaços livres e ocupados são concebidos a priori, concomitantemente, e de modo inter-relacionado. Como os espaços livres abundam nas CIMEs da América Latina, prevê-se o delineamento do conjunto - espaços livres e ocupados - através de uma normativa compatível e alinhada com a concepção da OSP, o que possibilita a conformação de um território como um todo integrado e sistêmico, englobando áreas de expansão urbana e áreas urbanas já consolidadas.

Desse modo, há a possibilidade de previsão e condução de um desenvolvimento urbano mais de acordo com dinâmicas biofísicas, socioculturais e urbanas, que ocorrem concretamente no território, com vistas a objetivos de ordenação urbana acordados coletivamente. A participação social prevista permite o conhecimento da paisagem local através do olhar de seus habitantes, assim como o acesso às intenções coletivas de transformação da paisagem futura.

Por outro lado, alguns desafios se destacam para a implementação da OsP nas CIMES latino-americanas, e correspondem à: 1) questões práticas - como a precariedade de dados existentes e a necessidade de obtê-los para a realização das análises pretendidas; 2) questões políticas - como as referentes à necessidade de apoio para a realização da participação da população no processo; a necessidade da existência de uma real intenção de se promover uma concertação coletiva em torno a objetivos e diretrizes de ordenação comuns e de normatizá-los; e a adequação do tempo das gestões políticas junto ao compromisso de desenvolver um plano a partir da OSP e implementá-lo em gestões posteriores.

Se, atualmente, essas questões são consideradas problemas para a implementação da OSP nas CIMES latino-americanas, também correspondem a questões que geram impactos negativos nos planos existentes, como, por exemplo, a falta de concretude e aplicabilidade dos mesmos. Se há realmente a intenção de conceber planos eficazes sob o ponto de vista de um desenvolvimento urbano comprometido de fato com a cidade e sua população, essas são questões que devem ser pensadas sob a luz de compromissos técnico e político com os recursos existentes biofísicos, socioculturais e urbanos - e o reconhecimento de seus valores junto aos desejos de sua gente. Se há essa intenção, territarios 43-Especial 
há a possibilidade de transformação desses desafios em oportunidades, ao se tornarem pontos prioritários para ações futuras dos governos locais de modo a saná-los.

Nesse sentido, acreditamos que a abordagem da OSP possa contribuir para a renovação na forma de pensar e planejar as CIMES da América Latina de modo mais integrado, sistêmico e participativo. Como desdobramentos da pesquisa, apontamos a necessidade de aprofundar as diretrizes sugeridas através da proposta de parâmetros objetivos que ajudem a traduzi-las em índices normativos.

\section{Agradecimentos}

Este trabalho foi realizado com o apoio da Coordenação de Aperfeiçoamento de Pessoal de Nível Superior (CAPES) por meio do suporte às atividades acadêmicas do Programa de Pós-graduação em Urbanismo da Faculdade de Arquitetura e Urbanismo da Universidade Federal do Rio de Janeiro, e com o apoio da Fundação de Amparo à Pesquisa do Estado do Rio de Janeiro (FAPERJ) por meio da concessão de bolsa de doutorado à aluna Juliana L. Motta Maia.. Agradecemos à Cynthia Tarrisse, Pauliane Durso e Isabel Almeida, pelas sugestões relativas ao desenvolvimento do artigo.

\section{Referências}

Ahern, J. (1995). Greenways as a planning strategy. Landscape and Urban
Planning, (33), 131-155. https://doi. org/10.1016/0169-2046(95)02039-V

Almandoz, A. (2015). Modernization, urbanization and development in Latin America (1900s-2000s). Routledge.

Barbedo, J., Miguez, M., van der Horst, D., \& Marins, M. (2014). Enhancing ecosystem services for flood mitigation: A conservation strategy for peri-urban landscapes. Ecology and Society, 19(2). https://doi.org/10.5751/ES-06482190254

Bellet, C., \& Llop, J. M. (2002). Ciudades intermedias. Perfiles y paulas. Ajuntament de Lleida.

Bellet, C., \& Llop, J. M. (2004). Miradas a otros espacios urbanos: las ciudades intermedias. Revista Electrônica de Geografía y Ciencias Sociales, VII(165), 26. http://www.ub.edu/geocrit/sn/ sn-165.htm

Benedict, M. A., \& McMahon, E. T. (2006). Green infrastructure. Linking landscapes and Communities. Island Press.

Berque, A. (1984). Paysage-empreinte, paysage-matrice: éléments de problématique pour une géographie culturelle. Espace Géographique, 13(1), 33-34.

Besse, J. M. (2006). Las cinco puertas del paisaje: ensayo de una cartografía de las problemáticas paisajeras contemporáneas. Em J. Manderuelo (Ed.), Paysaje y pensamiento (pp. 145-171). Abada Editores /CDAN.

Bolay, J. C., \& Rabinovich, A. (2004). Intermediate cities in Latin America risk and opportunities of coherent 
urban development. Cities, 21(5), 407-421. https://doi.org/10.1016/ j.cities.2004.07.007

Bolós, M. (Dir.) (1992). Manual de ciencia del paisaje. Masson.

Borsdorf, A., \& Hidalgo, R. (2010). From polarization to fragmentation. Recent changes in Latin American urbanization. Em P. Verkoren (Ed.), Decentralized development in Latin America: Experiences in localgovernance and local development (pp. 23-34). https://doi.org/10.1007/978-90481-3739-8_2

Capra, F. (1996). A teia da vida. São Paulo: Editora Cultrix-Pensamento Ltda.

Carmon, N., \& Shamir, U. (2010). Water-sensitive planning: Integrating water considerations into urban and regional planning. Water and Environment Journal, 24(3), 181-191. https://doi.org/10.1111/j.17476593.2009.00172.x

Carmona, M. (2009). Sustainable urban design: Principles to practice. International Journal of Sustainable Development, 12(1), 48-77. https:// doi.org/10.1504/IJSD.2009.027528

Cifuentes-Ruiz, P. A., \& Llop, J. M. (2015). Repensando la ciudad: estrategias de desarrollo urbano sostenible de las ciudades intermedias de América Latina. Revista Nodo, 9(19), 73-83.

Comisión Económica para América Latina y el Caribe (UN-CEPAL). (2017). Panorama multidimensional del desarrollo urbano en América Latina y el Caribe.
(L. Montero, J. García, Eds.). Naciones Unidas. https://repositorio.cepal.org/ bitstream/handle/11362/41974/1/ S1700257_es.pdf

Comisión Económica para América Latina y el Caribe (UN-CEPAL) \& Governo Italiano. (1998). Ciudades intermedias de América Latina y el Caribe: propuestas para la gestión urbana. ( $\mathrm{R}$. Jordan, D. Simioni, Comp.). Naciones Unidas. https://repositorio.cepal.org/ bitstream/handle/11362/31025/ S9800066_es.pdf

Cooper, R., Evans, G., \& Boyko, C. (2009). Designing sustainable cities. Blackwell Publishing.

Coy, M. (2003). Tendências atuais de fragmentação nas cidades latino-americanas e desafios para a política urbana e o planejamento urbano. Iberoamericana, III(11), 111-128.

Dematteis, G., \& Governa, F. (2005). Territorio y territorialidade em el desarrollo local. La contribución del modelo SLoT. Boletín de La A.G.E., (39), 31-58.

Dempsey, N., Bramley, G., Power, S., \& Brown, C. (2009). The social dimension of sustainable development: Defining urban social sustainability. Sustainable Development, 5(19), 289-300. https:// www.academia.edu/18196232/ The_social_dimension_of_sustainable_development_Defining_urban_social_sustainability

Dramstad, W., Olson, J., \& Forman, R. (1996). Landscape ecology principles territarios 43-Especial 


\section{territorias} 43-Especial in landscape architecture and land-use planning. Island Press/Harvard University/American Society of Landscape Architect.

Du-Plessis, C., \& Brandon, P. (2015). An ecological worldview as basis for a regenerative sustainability paradigm for the built environment. Journal of Cleaner Production, (109), 55-61.

Forman, R. (1995). Land mosaics - The ecology of landscape and regions. Cambridge University Press.

Gobster, P. H., \& Westphal, L. M. (2004). The human dimensions of urban greenways: Planning for recreation and related experiences. Landscape and Urban Planning, (68), 147-165.

González Bernardez, F. (1981). Ecología y paisaje. H. Blume Ediciones.

Guío Camargo, R. E. (2009). Función social y ecológica de la propiedad; características y alcances. Estudios En Derecho y Gobierno, 2(1), 51-63.

Hough, M. (1998). Naturaleza y ciudad. Gustavo Gili.

Ignatieva, M., Stewart, G. H., \& Meurk, C. (2011). Planning and design of ecological networks in urban areas. Landscape and Ecological Engineering, 7(1), 17-25. https://doi.org/10.1007/ s11355-010-0143-y

Jenks, M., \& Burgess, R. (2000). Compact cities: Sustainable urban forms for developing countries. Spon Press.

Jenks, M., \& Jones, C. (2010). Dimensions of the sustainable city. Springer. https:// doi.org/10.1007/978-1-4020-8647-2
Landscape Observatory of Catalonia. (2016). The landscape catalogues of Catalonya: Methodology. www.catpaisatge. net/fitxers/publicacions/metodologia_catalegs/Documents_3_ENG.pdf Laurie, M. (1975). Introducción a la arquitectura del paisaje. Gustavo Gili.

Liao, K. H. (2012). A theory on urban resilience to floods: A basis for alternative planning practices. Ecology and Society, 17(4). https://doi.org/10.5751/ES05231-170448

Llop, J. M., \& Bellet, C. (1999). Ciudades intermedias y urbanización mundial. Ajuntament de Lleida. http://www. ceut.udl.cat/wp-content/uploads/5. BOOKl_.pdf

Llop, J. M., \& Cruz, L. V. (2017). El derecho a la ciudad en el contexto de la agenda urbana para ciudades intermedias en el Ecuador. Universidad de Cuenca.

Lowenthal, D. (1975). Past time, present place: Landscape and memory. The Geographical Review, 15(1), 1-36.

Lynch, K. (1975). ¿De qué tiempo es este lugar? Gustavo Gili.

Mang, P., \& Reed, B. (2012). Designing from place: A regenerative framework and methodology. Building Research \& Information, 40(1), 23-38. https:// doi.org/10.1080/09613218.2012.6 21341

Mascaro, J. L. (2005). Loteamentos urbanos. Masquatro Editora.

McHarg, I. (1969). Design with nature. Doubleday \& Company. 
Miguez, M. G., Veról, A. P., Battemarco, B. P., Yamamoto, L. M. T., de Brito, F. A., Fernandez, F. F., \& Queiroz Rego, A. (2019). A framework to support the urbanization process on lowland coastal areas: Exploring the case of Vargem Grande - Rio de Janeiro, Brazil. Journal of Cleaner Production, 231, 1281-1293. https://doi. org/10.1016/j.jclepro.2019.05.187

Murcia, M. E., \& Scornik, C. O. (2016). Plan Base, hacia un método simplificado de planificación urbana - Ciudad de Paso de los Libres, Corrientes. Proyección, 19(10), 113-132.

Panerai, P. (2006). Análise Urbana. Brasília: Editora Universidade de Brasília.

Programa de las Naciones Unidas para los Asentamientos Humanos (ONU-Habitat). (2012). Estado de las ciudades de América Latina y el Caribe 2012: rumbo a una nueva transición urbana. https://unhabitat.org/sites/default/ files/download-manager-files/Estado de las Ciudades de América.pdf

Raymond, C. M., Frantzeskaki, N., Kabisch, N., Berry, P., Breil, M., Nita, M. R., Geneletti, D., \& Calfapietra, C. (2017). A framework for assessing and implementing the co-benefits of nature-based solutions in urban areas. Environmental Science and Policy, 77, 15-24. https://doi.org/10.1016/j. envsci.2017.07.008

Relph, E. (1976). Place and placelessness. London: Pion Limited.
Robinson, J., \& Cole, R. J. (2015). Theoretical underpinnings of regenerative sustainability. Building Research of Information, 43(2), 133-143. https:// doi.org/10.1080/09613218.2014.9 79082

Ruiz-Rivera, N., \& Lindert, P. (2016). Urban segregation in Latin America. Habitat International, 54, 1-2.

Santos, M. (2002). Por uma nova geografia. Edusp.

Scarano, F. R. (2017). Ecosystem-based adaptation to climate change: Concept, scalability and a role for conservation science. Perspectives in Ecology and Conservation, 15(2), 65-73. https:// doi.org/10.1016/j.pecon.2017.05.003 Schama, S. (1995). Landscape and memory. A. Knopf.

Stadel, C. (2000). Ciudades medianas y aspectos de la sustentabilidad urbana en la región andina. Espacio y Desarrollo, (12), 25-43. http://revistas.pucp.edu. pe/index.php/espacioydesarrollo/article/view/8082

Steinberg, F. (2002). Strategic urban planning in Latin America: Experiences of building and managing the Future. Support to Implementation of National Plans of Action (SINPA) Municipality of Santa Cruz de la Sierra, Bolivia and Institute for Housing and Urban Development Studies (IHS).

Steiner, F. (2007). Planning and urban design standards. John Wiley \& Sons, INC. territorios 43-Especial 
Tardin, R. (2013). System of open spaces: Concrete project strategies for urban territories. Springer. https://doi. org/10.1007/978-1-4614-4352-0

Tardin, R. (2018). Ordenação sistêmica da paisagem: uma aproximação metodológica. Em R. Tardin (Coord.), Análise, ordenação e projeto da paisagem: uma abordagem sistêmica (pp. 163-238). Rio Books/Prourb.

Tudor, C. (2014). An approach to landscape character assessment. Natural England. https://assets.publishing. service.gov.uk/government/uploads/ system/uploads/attachment_data/ file/691184/landscape-character-assessment.pdf

Vallecillo, S., Polce, C., Barbosa, A., Perpiña Castillo, C., Vandecasteele, I., Rusch, G. M., \& Maes, J. (2018). Spatial alternatives for green infrastructure planning across the EU: An ecosystem service perspective. Landscape and Urban Planning, 174, 41-54. https://doi.org/10.1016/j.landurbplan.2018.03.001 